\title{
Erratum to: An ABC transporter complex containing $S$-adenosylmethionine (SAM)-induced ATP-binding protein is involved in antibiotics production and SAM signaling in Streptomyces coelicolor M145
}

\author{
Sung-Kwon Lee $\cdot$ SangJoon Mo $\cdot$ Joo-Won Suh
}

Published online: 21 October 2012

(C) Springer Science+Business Media Dordrecht 2013

Erratum to: Biotechnol Lett

DOI 10.1007/s10529-012-0987-3

Unfortunately, acknowledgments had been missed out in the original publication. Please see the acknowledgment provided.
Acknowledgments This work was supported by a grant from the Next-Generation BioGreen 21 Program (No. PJ008093 and PJ008333), Rural Development Administration, Republic of Korea.

The online version of the original article can be found under doi:10.1007/s10529-012-0987-3.

S.-K. Lee · S. Mo · J.-W. Suh $(\bowtie)$

Division of Bioscience and Bioinformatics,

Myongji University, Yongin 449-728, Korea

e-mail: jwsuh@mju.ac.kr

S.-K. Lee

e-mail: saintk-lee@hanmail.net

S. Mo

e-mail: sjmo1107@hanmail.net 